\title{
Encontros reflexivos dialogais e o pensamento de Paulo Freire: por uma alternativa formativa transformadora
}

\author{
Erivânia Melo de Morais*-UFRN \\ Irene Alves de Paiva* - UFRN
}

\section{Resumo}

O presente estudo, tem como objetivo geral refletir sobre a relação do pensamento de Paulo Freire com um dos recurso metodológico intitulado de "Encontros Reflexivos Dialogais", desenvolvido durante a nossa pesquisa de campo de doutorado, e tem como objetivos específicos: apontar as contribuições de Paulo Freire para a formação dos encontros reflexivos, e apresentar análises preliminares do primeiro encontro com os licenciandos em Ciências Sociais da UFRN. Assim, optamos por uma metodologia qualitativa, com revisão de literatura, pautada nas concepções freireanas (1992; 2014; 2019), Borba (1998), Barbosa (1998), Morais (2019) e com parte da descrição realizadas nos encontros formativos. Para as análises, nos apoiamos numa perspectiva multirreferencial e nas reflexões de Paulo Freire, que nos indicou: a atualidade do seu pensamento, evidenciando a sua relevância contra toda forma de injustiça social, a necessidade de se constituir alternativas formativas transformadoras e na premência da formação de educadores críticos.

Palavra chave: Encontros Reflexivos Dialogais. Paulo Freire. Formação transformadora.

* Graduação em Ciências Sociais CCHLA/UFRN. Mestre em Educação pelo PPGED/UFRN. Doutorado em Ciências Sociais PPGCS/CCHLA/UFRN. Faz parte do grupo de pesquisa GEPEM (Grupo de Estudos de Praticas Educativas em Movimento). Experiência como professora substituta do IFRN/Campus Apodi/RN. E-mail: moraiserivania@gmail.com

** Graduação em Ciências Sociais pela Universidade Federal do Rio Grande do Norte. Mestre em Ciências Sociais pela Universidade Federal do Rio Grande do Norte. Doutorado em Educação pela Universidade de São Paulo. Pós-Doutorado na École Des Hautes Études em Sciencces Sociales (França). Atualmente é professora titular da Universidade Federal do Rio Grande do Norte. E-mail: irenealvesp@gmail.com 


\section{Reflective dialogal meetings and Paulo Freire's thinking: for a transformative training alternate.}

\section{Abstract}

The present study has the general objective of reflecting on the relationship of Paulo Freire's thought with one of the methodological resources entitled "Reflective Dialogal Meetings", developed during our doctoral field research with the specific objectives: point out the contributions of Paulo Freire's into the formation of these formative meetings, and to present preliminary analysis of the first meeting with the undergraduates in Social Sciences at UFRN. Thus, we opted for a qualitative methodological, with a literature review, based on the conceptions freireanas (1992; 2014; 2019), Borba (1998), Barbosa (1998), Morais (2019) and with some part of the description made in the formative meeting. For the analyzes, we supported ourselves in a multireferential perspective and in the reflections of Paulo Freire, that pointed out to us: the currentness of his thinking, showing its relevance against all forms of social injustice, the need to create transformative training alternatives and in the urgency of training critical educators.

Keyword: Reflective Dialogal Meetings. Paulo Freire. Transformative training.

\section{Reuniones de diálogo reflexivo y el pensamiento de Paulo Freire: para una alternativa de formaci- ón transformadora.}

\section{Resumen}

El presente estudio tiene el objetivo general de reflexionar sobre la relación del pensamiento de Paulo Freire con uno de los recursos metodológicos titulados "Reuniones de Diálogo Reflexivo", desarrollado durante nuestra investigación de campo de doctorado con los objetivos específicos: señalar las contribuciones de Paulo Freire para la formación de estas reuniones formativas, $\mathrm{y}$ presentar un análisis preliminar de la primera reunión con los estudiantes de um grado en Ciencias Sociales en la UFRN. Por lo tanto, optamos por una metodología cualitativa, con una revisión de la literatura, basada en las concepciones freireanas (1992; 2014; 2019), Borba (1998), Barbosa (1998), Morais (2019) y con alguna parte de las descripciones realizadas en la reuniones formativas. Para el análisis, nos 
apoyamos en una perspectiva multireferencial y en las reflexiones de Paulo Freire, que nos indicó: La actualidad de su pensamiento, subrayando su relevancia contra a todas las formas de injusticia social, la necesidad de crear alternativas de formación transformadoras y la urgencia de la formación del educadores críticos.

Palabras clave: Reuniones de Diálogo Reflexivo. Paulo Freire. Formación transformadoras.

\section{Notas preliminares}

Esta reflexão é um recorte da discussão metodológica da nossa pesquisa de doutorado, que trata da formação docente em ciências sociais, e dentre os estudos desenvolvidos, está a perspectiva de se constituir alternativas metodológicas que levem os estudantes em formação, a um processo de autorização e de transformação dialética da prática, ou seja, que haja dentro de uma práxis, as relações consciência - mundo, como nos apresenta Freire (1992), rompendo com modos mecânicos de interpretar a realidade.

Hodiernamente, estamos vivenciando mudanças profundas, implicadas por impasses contemporâneos, que perpassam desde alterações no campo político onde desde 2016 e consolidado em 20181, reconfiguram-se as disputas hegemônicas, que fomentou de forma mais incisiva um projeto neoliberal da sociedade, até o presente momento, e ainda impactos sanitários ${ }^{2}$ que tem impelido um novo modo de comportamento e relações sociais, que possivelmente terão rebatimentos decisivos nas políticas educacionais e de formação de docentes que nesses últimos anos tem sido abreviado por políticas de contenção do atual governo.

Nesse sentido, pensar alternativas formativas que possam complementar a formação e o debate docente de forma crítica, reflexiva e transformadora, levando os licenciandos em processo

Com o Impeachment da Presidente Dilma Rousseff e com a eleição do Jair Bolsonaro.

2 Decorrentes do Covid-19 que tem levado o sistema educacional brasileiro a buscar alternativas de ensino remoto, com auxílio de rotinas de atividades semanais e das Tecnologias, o que tem refletido diversas contradições e aprofundamentos das desigualdades. 
formativo a percepção e a compreensão da função social do professor e do seu papel na sociedade frente a essas mudanças, se coloca como um esforço necessário dentro da atual conjuntura.

Assim definimos como objetivo geral refletir sobre a relação do pensamento de Paulo Freire com um dos recursos metodológico "Encontros Reflexivos Dialogais - ERD”, desenvolvido no decorrer da nossa pesquisa de campo de doutorado e que foi realizado na forma de um curso de extensão com sete estudantes da licenciatura em Ciências Sociais da Universidade Federal do Rio Grande do Norte - UFRN, e delineamos como objetivos específicos deste recorte reflexivo: apontar as contribuições do pensamento de Paulo Freire para a constituição dos ERD; e apresentar uma breve reflexão do nosso primeiro encontro que teve como ponto de partida pensamentos de Paulo Freire, retirados da obra "Pedagogia da Autonomia: Saberes necessários à prática educativa”.

Desse modo, buscaremos analisar os dados preliminares do primeiro Encontro formativo com os licenciandos de Ciências Sociais da UFRN, a partir de Bardin (2010) com a análise de conteúdo dos dados obtido durante a pesquisa de campo, que nesse momento serão apresentados de forma interpretada e acionando reflexões e concepções teóricas freireanas.

Destarte, sistematizaremos o texto em dois momentos, o primeiro intitulamos de "Os Encontros Reflexivos Dialogais e o pensamento freireano: constituindo alternativas metodológicas transformadoras" onde buscamos ressaltar as contribuições do pensamento de Paulo Freire para a constituição desse recurso metodológico, utilizado como um processo formativo complementar para os estudantes das ciências sociais, em seguida teremos "Os ERD como uma alternativa formativa possível: reflexões preliminares", que apresentaremos algumas das discussões que foram levantadas durante o primeiro Encontro formativo. 


\section{Os encontros reflexivos dialogais e o pensamento freireano: constituindo alternativas metodológicas transformadoras?}

Os Encontros Reflexivos Dialogais - ERD ${ }^{3}$, foram constituídos durante nossa pesquisa de doutorado no Programa de Pós-Graduação em Ciências Sociais da Universidade Federal do Rio Grande do Norte - UFRN, e aconteceu em formato de curso de extensão, onde os estudantes da licenciatura em ciências sociais foram convidados a participar dessa formação que teve como título "Formação e profissão de professores em ciências sociais: perspectivas teóricas-metodológicas e os desafios da prática", que a princípio foi planejada a partir do embasamento teórico dos grupos focais onde construiríamos questões para serem debatidas pelos participantes, entretanto, no decorrer de nossos estudos e aprofundamento epistêmico pautado na teoria da multirreferencialidade, que de acordo com Ardoino (1998) e em linhas gerais, seria refletir a realidade numa perspectiva plural e buscar um processo de autorização na pesquisa. Dessa forma,

Ao nos aproximarmos dos grupos focais em nossos estudos doutorais, passamos a compreender que, apesar de sua estrutura ser de um todo relevante, não era o que pretendíamos realizar com os participantes da nossa pesquisa, tendo em vista que já estávamos imersos nas contribuições da abordagem multirreferencial, que a todo momento nos chamava para um processo de autorização e de nos colocarmos enquanto sujeitos coautores e não apenas como agentes reprodutores de instrumentalidades metodológicas, mas que iniciássemos um caminhar de aprendizagens possíveis, de nos permitir a pensar, a repensar e a ressignificar os nossos recursos metodológicos. (MORAIS, 2019, p. 197)

Assim, a partir das pesquisas, estudos teóricos e epistemológicos, passamos a perceber que a forma como estávamos pensando

Para melhor compreender como o caminho de constituição dos ERD, ler a revista Educação e Linguagem, o v.22, n2 de 2019, onde encontra-se o texto "Encontros Reflexivos Dialogais (ERD): um recurso metodologico possível nas ciências humanas e sociais. (MORAIS, 2019) 
a formação dos estudantes, seria mais uma vez, a reprodução das formações realizadas, ou seja, com estruturas de aulas prontas, com possíveis temas para o debate previamente selecionados, que não correspondiam a proposta metodológica que estávamos tentando construir com os ERD.

Dessarte, passamos a refletir como seria possível realizarmos uma formação que fosse ao mesmo tempo, significativa, orientada pela concepção do diálogo freireano, permitindo uma compreensão dinâmica e processual, em que os participantes pudessem ao mesmo tempo atuar na composição de planejamentos e que posteriormente utilizassem esses parâmetros como organizadores das suas práticas pedagógicas e na colaboração e organização de programa escolares.

Então, como poderíamos realizar uma formação, cuja autoria e co-autoria tivesse a participação coletiva de todos os envolvidos na pesquisa?

O caminho encontrado emergiu das contribuições de Paulo Freire, que ao longo de sua trajetória como educador crítico, nos permitiu pensar, repensar, ressignificar a formação de docente a partir da leitura do mundo e da realidade social. Assim, buscamos apoio na sua concepção de prática docente, que para além de um método nos permite perceber a ação educativa crítica e a postura ética, humana e política do educador e da educadora.

A concepção freireana, nos permite compreender as nuances de um pensamento que carrega perspectivas plurais para pensar a educação e a formação docente. Pensamento esse, que dialoga com a política, com o social, com a afetividade do eu e do outro, com as relações sociais entre atores diferentes, com a esperança crítica de transformar, não de modo ingênuo de pensar que sozinho transforma-se o mundo, mas de compreender que a partir de uma prática, que é coletiva, é possível modificar pequenas engrenagens sociais, que aprisionam e garantem a manutenção da desigualdade, seja ela do acesso à escola ao conhecimento.

Nesse ínterim, propor as perspectivas de formação, requer um esforço teórico-prático, e este por sua vez, precisa estar rela- 
cionado numa busca transformadora da realidade, ou seja, numa relação dialética que nos leve a atuar sobre a realidade, e para isso, é importante que a nossa formação nos coloque de encontro com repertórios de conhecimentos plurais, capazes de nos transformar, de nos conscientizar, de nos mobilizar e, sobretudo de não nos deixar pessimistas, a ponto de não acreditarmos que a educação pode ser um caminho de mudança, e que enquanto prática elucidada "a educação soz̧inha, porém, não faz a transformação do mundo, mas esta a implica”. (FREIRE, 1992, p. 32).

A educação de acordo com Freire (2014a) é uma resposta da finitude a infinitude, por ser, o ser humano inacabado, compreende essa incompletude e a formação como prática intencional e libertária passa a ser parte do processo de conscientização ou não, desse ser, que pode ser levado a reproduzir as lógicas dominantes de forma naturalizada.

Assim, é essencial viabilizar, formações que constituam esse educador crítico capaz de realizar uma leitura da realidade, de compreender os antagonismos sociais, de pensar as disputas hegemônicas carregadas de discursos neoliberais e neoconservadores, segundo Freire (1992) "cheios de modernidade", que não tem força para acabar com as lutas sociais, nem com os conflitos existentes, porque a luta é uma categoria histórica, que "Tem, por isso, historicidade. Muda de espaço-tempo a espaço tempo. A luta não nega a possibilidade de acordos, de acertos entre as partes antagônicas. Os acordos fazem parte igualmente da luta”. (FREIRE, 1992, p. 93).

À vista disso apontamos preliminarmente, algumas reflexões da formação docente, a partir das nossas análises do primeiro Encontro Reflexivo Dialogal - ERD com os estudantes de ciências sociais da UFRN.

\section{Os ERD como uma alternativa formativa possí- vel: reflexões preliminares.}

Os "Encontros Reflexivos Dialogais - (ERD)", aconteceram em seis momentos presenciais, nos quais, os participantes da pes- 
quisa tiveram uma enorme contribuição, desde a constituição do planejamento, dos objetivos, da formação dos eixos que seriam discutidos durante os nossos diálogos. Pode-se afirmar que, esse é um ponto central desse processo, porque se coloca como uma formação que é coletiva e que compreende a relevância de todos, assim,

Os Encontros Reflexivos Dialogais - ERD - precisam ser entendidos antes de qualquer coisa como um processo de autorização, que é flexível, e que pode se ajustar a pesquisas que busquem para além de uma discussão com base em temática ou questão, suscitar um processo formativo em que os participantes sejam parte e se sintam parte do momento dialogado. (MORAIS, 2019, p. 201)

Nesse sentido, passamos a compreender a importância de delinear o nosso caminho na pesquisa e não apenas de reproduzir recursos prontos, mas de nos implicarmos como autoras desse processo. Assim concordamos com Borba (1998), que afirma que o fazer ciência, o criar, é que definirá a bricolagem metodológica e não o contrário, ou seja, é no campo de pesquisa que se reflete e elabora-se metodologias e não o inverso.

Para a formação dos Encontros, passamos por diversos processos, até a elaboração do projeto do curso de extensão, no qual os estudantes se inscreveram para participar. $\mathrm{Na}$ totalidade, tivemos sete estudantes ${ }^{4}$ do curso de ciências sociais, que participaram dos momentos formativos, desses, três eram mulheres caracterizando $43 \%$ e quatro homens representando $57 \%$, com idades entre 21 anos a 37 anos sinalizando um grupo experiente.

Esses estudantes, na ocasião em que foi realizado os Encontros Reflexivos Dialogais - ERD estavam cursando o Estágio Supervisionado de Formação docente IV e eram bolsistas da resi-

Antes de chegarmos nesses estudantes que participaram dos ERD, aplicamos anteriormente outros recusos metodologicos com 22 licenciandos das ciências sociais, e desses apenas sete tiveram interesse em participar da formação. Esses dados estão sendo avançados na nossa tese que esta em processo. 
dência pedagógica ${ }^{5}$ ou do PIBID $^{6}$, sendo relevante para a dinâmica dos encontros, porque trouxeram as experiências partilhadas dos seus respectivos envolvimentos com essas políticas de formação, que lhes proporcionaram estar em contato com a prática docente anterior aos estágios, como no caso do PIBID.

Que foi uma política de fomento à docência, que proporciona aos estudantes uma aproximação da prática e ainda o contato com um repertório de conhecimentos pedagógicos e específicos do fazer docente, permitindo ainda "aos bolsistas uma formação ampla e plural em diversos espaços formativos para além da Universidade, rompendo com a ideia de que conhecimento só se produz na academia”. (MORAIS; MELO, 2018, p. 282).

Por conseguinte, nosso primeiro Encontro Reflexivo Dialogal, denominamos de "acolhimento reflexivo", onde cada um se apresentou, falou sobre o que esperava desse momento, das angústias da prática docente em ciências sociais e lhes foi entregue um material com o "diário formativo" para que registrassem suas reflexões, seus anseios, seus pensamentos no decorrer dos encontros ou em outros momentos que os fizessem lembrar desses nossos momentos de formação.

Em seguida, fizemos um questionamento, sobre: "quando pensamos numa prática reflexiva, que nos movimenta a compreender a realidade do aluno, o que vocês pensam?", e após alguns minutos de silêncio na roda de conversa, surge uma resposta tímida, "Paulo Freire"?!, dita como uma pergunta e uma certeza, e assim, iniciamos o nosso primeiro diálogo a partir de citações do livro "Pedagogia da Autonomia: saberes necessários à prática educativa", explicado anteriormente,

5 O Programa Residencia Pedagógica foi instituido através da "Portaria GAB $\mathrm{n}^{\circ} 38$ de 28 de fevereiro de 2018, com a finalidade de formentar a formação inicial.

6 O Programa Institucional de Bolsa de Iniciação a Docência é um programa federal criado para que os estudantes iniciassem a prática docente nos primeiros semestres dos cursos de suas respectivas licenciaturas. O artigo de Melo e Morais (2018) O programa Institucional de Bolsas de Iniciação à Docência - PIBID e a valorização da formação docente na UFRN/Campus Central. Momento: diálogos em educação. (MELO; MORAIS, 2018) 
como sendo um caminho a ser tomado para iniciar a reflexão sobre a prática docente, sem, necessariamente levar uma temática pronta, mas por entender a contribuição de Paulo Freire para a educação e formação docente, a partir de uma pratica pedagógica libertadora e democrática, em que o conhecimento somente se constrói na ação coletiva dos sujeitos envolvidos.

Assim, decidimos - no sentido freireano de tomar para si a responsabilidade e a implicação ética e política - a partir de nosso estudo da obra Pedagogia da Autonomia, destacar vinte citações das quais Paulo Freire nos convida a pensar a prática reflexiva do educador crítico, que se propõe com sua reflexão-ação-reflexão, transformar o mundo a partir da transformação das pessoas e as colocamos em uma caixa, e assim, os estudantes retiraram as citações para dessa forma iniciarmos o primeiro Encontro Reflexivo Dialogal.

A medida em que retiravam as citações, iniciavam a reflexão e o diálogo, e todos os participantes poderiam discordar, complementar, concordar ou acrescentar, uma vez que, este momento foi pensado como uma forma de organização coletiva do conhecimento, conforme demostrado abaixo:

Tabela 1 - Citações problematizadas no Encontro 1.

\begin{tabular}{|l|l|}
\hline $\begin{array}{l}\text { Ordem } \\
\text { de } \\
\text { citação }\end{array}$ & Citação \\
\hline 1 & $\begin{array}{l}\text { "Quem ensina aprende ao ensinar e quem aprende ensina ao aprender" } \\
\text { (FREIRE, 2019, p. 25). }\end{array}$ \\
\hline 2 & $\begin{array}{l}\text { "O educador democrático não pode negar-se o dever de, na sua prática do- } \\
\text { cente, reforçar a capacidade crítica do educando, sua curiosidade, sua insub- } \\
\text { missão [...]" (FREIRE, 2019, p. 28), }\end{array}$ \\
\hline 3 & $\begin{array}{l}\text { "A prática docente, especificamente humana, é profundamente formadora, } \\
\text { por isso, ética" (FREIRE, 2019, p. 64), }\end{array}$ \\
\hline 4 & $\begin{array}{l}\text { "O educador que escuta aprende a difícil lição de transformar o seu discurso, } \\
\text { às vezes necessário, ao aluno em uma fala com ele [...]" (FREIRE, 2019, p. 111) }\end{array}$ \\
\hline 5 & $\begin{array}{l}\text { "Saber que ensinar não é transferir conhecimento, mas criar as possibilidades } \\
\text { para a sua própria produção ou a sua construção [...]" (FREIRE, 2019, P. 47). }\end{array}$ \\
\hline
\end{tabular}

Fonte: Paulo Freire, "Pedagogia da Autonomia" de 2019. Elaborado pelas autoras. 
As citações foram lidas ao serem retiradas, dando início aos debates reflexivos sobre a prática docente, assim, o primeiro participante, ao ler o pensamento "Quem ensina aprende ao ensinar e quem aprende ensina ao aprender" (FREIRE, 2019, p. 25), sinalizava que os estudantes aprendem cada um à sua maneira e que, a partir de sua experiência no estágio supervisionado, tentava construir o ensino de sociologia de forma mais significativa, ou seja, que fosse capaz de permitir a construção de sentidos e leitura crítica da realidade social. Assim, "O educando se reconhece conhecendo os objetos, descobrindo que é capaz de conhecer, assistindo à imersão dos significados em cujo processo se vai tornando também significador crítico". (FREIRE, 1992, p. 47).

Seguindo essa reflexão, Barbosa (1998) chama atenção para a importância de nos contrapormos a desautorização do outro, muitas vezes, praticadas de forma imperceptível e inconsciente, quando negamos aos estudantes a construção do pensamento autônomo. O autor ainda destaca, a relevância de se resgatar uma educação da vida da pessoa humana, denominando de "educação para a formação de autores-cidadão” (BARBOSA, 1998), na qual explica que,

Autor-cidadão, significa referir-se a esta árdua e complexa tarefa mobilizadora do sujeito como todo se propõe formá-lo (forma-se) para uma maneira integrada de atuar no mundo, de se posicionar no público, de se comportar no privado, de agir no trabalho, no sindicato, na igreja [...]. (BARBOSA, 1998, p.8)

Assim, resgatar ou ressignificar essa perspectiva de autoria e de formar autores-cidadãos no processo de ensinar/aprender e aprender/ensinar é possibilitar aquilo que Paulo Freire destacou sobre o ato de estudar e aprender, que "É preciso, pois, que os educandos descubram e sintam a alegria nele embutida, [...]" (FREIRE, 1992, 83)

$\mathrm{Na}$ segunda leitura da citação "O educador democrático não pode negar-se o dever de, na sua prática docente, reforçar a capacidade crítica do educando, sua curiosidade, sua insubmissão [...]" 
(FREIRE, 2019, p. 28), o segundo participante atentava que, para os estudantes das ciências sociais, essa compreensão de se formar um educador democrático fosse mais acessível do que em outros cursos, tendo em vista que, desde o início da graduação eram provocados e estimulados pelas leituras teóricas da sociologia, da política e da antropologia, que os permitiam repertórios de conhecimentos diversos para que pudessem ler a realidade.

$\mathrm{Na}$ terceira citação tivemos "A prática docente, especificamente humana, é profundamente formadora, por isso, ética". (Freire, 2019, p. 64), assim, a participante salientou, sobre os desafios de uma prática docente humana, e exemplificou as dificuldades que surgem na sala de aula e em ter que lidar com estudantes do ensino médio, que não se interessavam pela disciplina e que não faziam as atividades e por isso, buscava dialogar sobre o que estava impossibilitando o cumprimento da tarefa, refletindo ainda sobre os sentidos da disciplina de sociologia e o envolvimento dos estudantes de forma que pudesse ressignificá-los, destacando que a prática docente é essa eterna formação, que é aprendida na universidade, mas sobretudo com a experiência da docência.

O que movimentou o debate a partir dessa terceira citação foi: Como desenvolver o ensino de sociologia de maneira que chegue ao estudante e que o interessasse? Que não o afastasse da sala de aula? Os participantes a partir das suas reflexões buscaram compreender o estudante enquanto um sujeito que tem uma história, que tem uma subjetividade, mas que permeia o mundo da objetividade, tendo em vista que, "a objetividade dicotomizada da subjetividade, a negação desta na análise da realidade ou na ação sobre ela, é objetivismo" (FREIRE, 2014, 51).

Desse modo, os participantes perceberam a relevância de se problematizar temas da sociologia a partir da realidade dos estudantes e que este deveria ser um caminho a ser pensado, um ensino que partisse da realidade na relação com sua totalidade, tendo em vista, a necessidade de reconhecer que o estudantes do Ensino Médio das Escolas da Rede Básica de Ensino na qual atuam em Natal/Rio 
Grande do Norte, vivencia uma realidade, uma cultura que é dele e nesse sentido, é crucial encontrar caminhos, para que o ensino de sociologia entre nesses espaços de forma alcançável e que esse estudantes consiga acionar as problematizações do campo sociológico, tomando como ponto de partida, a realidade social.

O próximo participante apresenta a quarta citação que versa sobre "O educador que escuta aprende a difícil lição de transformar o seu discurso, às vezes necessário, ao aluno em uma fala com ele [...]" (FREIRE, 2019, p. 111), e na sua reflexão considera que, muitas vezes, falar não é se comunicar, que o professor ministra cinquenta minutos de uma aula e não consegue se comunicar com o educando, porque não constituiu na sua comunicação uma situação dialética, de troca, de interação, de diálogo, ou seja, de verbalizar uma ideia, concepção e o estudante indagar, questionar, se contrapor, ou complementar esse pensamento, e assim, fomentar aquilo que Freire (2014) designa de práxis docente.

Assim a relação dialógica entre professor e educando não pode ser convertida em bate papo como salienta Freire (1992), mas que provoque a curiosidade epistemológica, e que desenvolva o pensamento crítico e consciente do estudante, assim "O diálogo pedagógico implica tanto o conteúdo ou objeto cognoscível em torno de que gira quanto a exposição sobre ele feita pelo educador ou educadora para o educandos". (FREIRE, 1992, p. 118).

É importante observar o quanto é essencial o dialogo entre professor e educando e que essa comunicação não se limita ao ato de falar, mas de se relacionar num sentido mais amplo, de respeitar que esse estudante, traz em si um saber, uma cultura, valores e crenças que são singulares, e que deve ser respeitado como salienta, Freire (2019).

E por fim a nossa quinta citação, "Saber que ensinar não é transferir conhecimento, mas criar as possibilidades para a sua própria produção ou a sua construção [...]" (FREIRE, 2019, P. 47), que foi interpretada pelo participante como uma experiência transformadora da prática docente, e exemplificou que durante a regência 
do estágio supervisionado ao preparar uma aula com sua colega de estágio, sobre a temática "educação", decidiram iniciar a reflexão ouvindo as ideias dos estudantes que foram registrados no quadro.

A partir disso, passaram a realizar os debates até chegar em um dos pontos que havia sido sistematizado no planejamento da aula e que fazia parte da problematização sociológica, relacionado a relação dos processo de socialização primária e secundária, que de acordo com o participante, foi significativo esse momento, porque os estudantes do ensino médio, sinalizaram exemplos que os licenciandos não haviam pensado e também reflexões que aprofundaram o debate e nesse sentido construíram possibilidades de aprendizagens coletivamente.

Entendendo que, para além de uma educação meramente "bancária", que se preocupa em garantir a continuidade de um processo de opressão e de não conscientização do educando, é imperativo que o educador crítico na perspectiva freireana, a partir de um processo de reflexão-ação-reflexão de sua prática, compreenda que ensinar não é depositar, ou transmitir, mas a de permitir, que esses educandos problematizem suas relações com o mundo e assim, "identifica-se com o próprio da consciência que é sempre consciência de". (FREIRE, 2014, p. 94).

Assim para dar continuidade aos outros encontros, os estudantes na sua curiosidade, nas suas angústias registraram perguntas e/ou temas que gostariam de debater nos demais momentos, que tiveram a participação de docentes/pesquisadores - Docentes da Rede Básica Estadual e Municipal, e do Departamento de Ciências Sociais da UFRN - que se propuseram a participar como convidados, para o enriquecimento do debate.

E foi desta forma, que os demais Encontros Reflexivos Dialogais - ERD, foram conduzidos, a partir dos interesses, dos saberes, das inquietações dos estudantes da licenciatura em Ciências Sociais da Universidade Federal do Rio Grande do Norte - UFRN, construindo de forma coletiva, reflexões e conhecimentos acerca da prática docente e sobre a relevância de criar possibilidades de 
transformação da realidade social, a partir de uma educação problematizadora que permita a todas as pessoas a pronunciar o mundo e modificá-lo como salienta Freire (2014) que aprofunda esta perspectiva em "Educação como prática da Liberdade", sendo esses princípios norteadores e fundamentais para construção de uma práxis pedagógica transformadora.

\section{Considerações finais}

Esta reflexão se propôs a compartilhar avanços preliminares de um dos recursos metodológicos utilizados, em um dos momentos do nosso campo de pesquisa, durante o nosso doutoramento. A este recurso denominamos de Encontros Reflexivos Dialogais ERD, que partiu de um processo de ressignificação dos grupos focais e grupos reflexivos e da nossa imersão epistemológica na perspectiva multirreferencial, como já salientamos em outros estudos publicados pela revista Educação e Linguagem. (MORAIS, 2019)

Mas cabe destacar neste trabalho, que os Encontros Reflexivos Dialogais, que estão sendo avançados e aprofundados na nossa tese, agregam a contribuição da concepção freireana para a sua composição na qual dialoga com a perspectiva multirreferencial, em que ambas as perspectivas permitem um processo de autorização de si, e de autoria no sentido de criar uma nova práxis. Assim, os ERD, carrega consigo a perspectiva da autorização, do instituinte, de criar para além do instituído, e que a partir do contato com os estudantes, com o objeto da pesquisa, desenvolveu caminhos próprios para uma formação dialética para eu-mundo, ou seja, uma formação que perpassasse a mim enquanto ser no mundo e ser para o mundo.

Os ERD levam os esteios do pensamento de Paulo Freire, seja na busca de uma formação transformadora, que permita a esses educandos em processo formativo, constituir-se enquanto educador crítico e o otimismo de pensar que, uma alternativa formativa crítica, reflexiva pode complementar os demais processos na consolidação de uma perspectiva transformadora da realidade. E que a partir das trocas de conhecimento, de saberes, das reflexões, 
dos diálogos, da leitura da realidade social que esses estudantes em formação se apoiaram em bases teóricas, epistêmicas para pensar as suas metodologias, suas práticas, a escolas enquanto espaço plurais, mas também de refletir que "A sua pluralidade não é só em face dos diferentes desafios que partem do seu contexto, mas em face de um mesmo desafio" (FREIRE, 2011, p. 40), que perpassa pela conscientização de que não há repostas, nem ações padronizadas.

Assim, construir alternativas formativas transformadoras, que nos permita agregar conhecimentos diversos, para compreendermos os desafios postos pela realidade é basilar para que a partir desses repertórios de saberes, possamos atuar na realidade. Paulo Freire (1992) nos ensina ainda hoje, que educadores críticos exigentes, coerentes com o exercício da reflexão com sua prática educativa ou sobre a própria atuação, a entende na sua totalidade.

Nesse sentido, evidenciamos como parte da reflexão realizada neste texto, três perspectivas, primeiro: a atualidade do pensamento de Paulo Freire, que nos últimos anos tem sido objeto de constantes ataques por parte de grupos neoconservadores, predispostos a desfocar a relevância do pensamento desse grande autor brasileiro, mundialmente conhecido e reconhecido Patrono da Educação Brasileira pela Lei 12. 612 de 13 de abril de 2012, no então governo da presidente Dilma Rousseff. E que desenvolveu projetos de educação voltados a pensar formas de democratizar o ensino, de incluir, de respeitar os saberes do outro, de desenvolver formas de romper com a lógica do privilégio dominante, garantindo às classes populares a possibilidade de aprender a partir do seu mundo, instituindo concepções de justiça e igualdade social.

Segundo, a premência de pensar e constituir formas alternativas de formações transformadoras, pautadas na concepção freireana, que apesar do esforço, como dito anteriormente, de não levar em consideração a sua trajetória, é necessário que nós enquanto educadores críticos continuemos a afirmar e reafirmar a relevância do seu pensamento e que mais do que reverberação, que reflita na nossa prática, na nossa ação, e foi isso que tentamos realizar com 
os Encontros Reflexivos Dialogais, de ser um espaço de "Compromisso com o mundo, que deve ser humanizado para a humanização dos homens com estes e com a história" (FREIRE, 2014a, p. 22)

E por fim, mas não menos relevante, o nosso compromisso educativo, social e humano de participar da formação de educadores críticos, engajados da sua função social transformadora, de compreender a autenticidade da prática de ensinar- aprender, de se constituir enquanto educador democrático, reforçando no educando a sua insubmissão e exaltando a sua liberdade e conscientização, de entender que sua tarefa não se restringe a "ensinar conteúdos", mas ensinar a pensar. Por isso, reiteramos sempre: Paulo Freire vive!

\section{Referências}

ARDOINO, J. Abordagem multirreferencial (plural) das situações educativas e formativas. In:_BARBOSA, J. G. (Coord.). Multirreferencialidade nas ciências e na educação. São Carlos: Editora da UFSCar, 1998. p. 24-41.

BORBA, Sérgio da Costa. Aspectos do conceito de multirreferencialidade nas ciências e nos espaços de formação. In: BARBOSA, J. G. (Org). Reflexões em torno da abordagem multirreferencial. São Carlos: Editora da UFSCar, 1998. p. 11-19.

FREIRE, Paulo. Pedagogia da Autonomia: Saberes necessários à prática educativa. 59 ed. Rio de Janeiro/São Paulo: Paz e Terra, 2019.

FREIRE, Paulo. Pedagogia da Esperança: um reencontro com a pedagogia do oprimido. 15 ed. Rio de Janeiro: Paz e Terra. 1992.

FREIRE, Paulo. Pedagogia do Oprimido. 58 ed. Rio de Janeiro: Paz e Terra. 2014.

FREIRE, Paulo. Educação e Mudança. 36 ed. São Paulo: Paz e Terra, 2014a.

FREIRE, Paulo. Educação como Prática para Liberdade. Rio de Janeiro: Paz e Terra, 2011.

MORAIS, Erivania Melo de. Encontros reflexivos dialogais (ERD): Um recurso possível nas ciências humanas e sociais. Educação \& Linguagem. v. 22, n. 2. p. 193-206, jul.-dez. 2019. 
MORAIS, Erivania Melo de; MELO, Elda Silva do Nascimento. O programa Institucional de Bolsas de Iniciação à Docência - PIBID e a valorização da formação docente na UFRN/Campus Central. Momento: diálogos em educação, v. 27, n. 2, p. 264-284, mai./ago, 2018.

SOARES, Magda. Alfabetização e letramento. 6. ed. São Paulo: Contexto. 2011. 